\title{
What are the drivers of recurrent cholera transmission in Nigeria? Evidence from a scoping review
}

Kelly Osezele Elimian ${ }^{1,2^{*}}$, Somto Mezue ${ }^{2}$, Anwar Musah³, Oyeronke Oyebanji ${ }^{1}$, Ibrahima Soce Fall ${ }^{4}$, Sebastian Yennan ${ }^{1}$, Michel Yao ${ }^{4}$, Patrick Okumu Abok ${ }^{4}$, Nanpring Williams' ${ }^{1}$, Lynda Haj Omarr ${ }^{4}$, Thieno Balde ${ }^{4}$, Kobina Ampah', Ifeanyi Okudo ${ }^{5}$, Luka Ibrahim ${ }^{5}$, Arisekola Jinadu' ${ }^{1}$, Wondimagegnehu Alemu ${ }^{5}$, Clement Peter ${ }^{5}$ and Chikwe Ihekweazu ${ }^{1}$

\begin{abstract}
Background: The 2018 cholera outbreak in Nigeria affected over half of the states in the country, and was characterised by high attack and case fatality rates. The country continues to record cholera cases and related deaths to date. However, there is a dearth of evidence on context-specific drivers and their operational mechanisms in mediating recurrent cholera transmission in Nigeria. This study therefore aimed to fill this important research gap, with a view to informing the design and implementation of appropriate preventive and control measures.

Methods: Four bibliographic literature sources (CINAHL (Plus with full text), Web of Science, Google Scholar and PubMed), and one journal (African Journals Online) were searched to retrieve documents relating to cholera transmission in Nigeria. Titles and abstracts of the identified documents were screened according to a predefined study protocol. Data extraction and bibliometric analysis of all eligible documents were conducted, which was followed by thematic and systematic analyses.
\end{abstract}

Results: Forty-five documents met the inclusion criteria and were included in the final analysis. The majority of the documents were peer-reviewed journal articles (89\%) and conducted predominantly in the context of cholera epidemics (64\%). The narrative analysis indicates that social, biological, environmental and climatic, health systems, and a combination of two or more factors appear to drive cholera transmission in Nigeria. Regarding operational dynamics, a substantial number of the identified drivers appear to be functionally interdependent of each other.

Conclusion: The drivers of recurring cholera transmission in Nigeria are diverse but functionally interdependent; thus, underlining the importance of adopting a multi-sectoral approach for cholera prevention and control.

Keywords: Cholera, Scoping review, Drivers, Transmission, Multi-sectoral

\footnotetext{
* Correspondence: kellyelimian@gmail.com

${ }^{1}$ Nigeria Centre for Disease Control, Abuja, Nigeria

2University of Benin, Benin, Nigeria

Full list of author information is available at the end of the article
}

(c) The Author(s). 2020 Open Access This article is licensed under a Creative Commons Attribution 4.0 International License, which permits use, sharing, adaptation, distribution and reproduction in any medium or format, as long as you give appropriate credit to the original author(s) and the source, provide a link to the Creative Commons licence, and indicate if changes were made. The images or other third party material in this article are included in the article's Creative Commons licence, unless indicated otherwise in a credit line to the material. If material is not included in the article's Creative Commons licence and your intended use is not permitted by statutory regulation or exceeds the permitted use, you will need to obtain permission directly from the copyright holder. To view a copy of this licence, visit http://creativecommons.org/licenses/by/4.0/ The Creative Commons Public Domain Dedication waiver (http://creativecommons.org/publicdomain/zero/1.0/) applies to the data made available in this article, unless otherwise stated in a credit line to the data. 


\section{Background}

Cholera is an acute watery diarrhoeal disease that is caused by the ingestion of food or water contaminated with the toxigenic strains of Vibrio cholerae ( $V$. cholerae) serogroups O1 or O139 [1]. Cholera is often characterised by a rapid onset of watery diarrhoea, with or without vomiting, and an extensive dehydration [2]. When prompt rehydration therapy is not administered for severe cases, cholera can result in severe clinical sequel including lethargy, unconsciousness, confusion, and a drop in blood pressure and circulatory shock as well as death [3]. The case fatality rate (CFR) from untreated cholera cases can be as high as $30-50 \%$, although the value could be as low as $1 \%$ with adequate and prompt care [2].

Modelling exercises indicate that cholera burden remains a global threat, with an estimate of about 2.86 million suspected cases and 95,000 deaths per year [4]. Evidence indicates that these figures could be higher if social, political and economic disincentives for reporting cholera cases are taken into account [5]. Nonetheless, cholera, being an indicator of inequity and social development [6], disproportionately affects low- and middleincome countries. Since the first report of a cholera outbreak in Nigeria in 1970 [7], the country has remained endemic for the disease with several epidemics and high attack rates and CFRs. Moreover, cholera in Nigeria has been increasingly linked with ongoing armed-conflicts, environmental and climatic changes, rapid urbanization and increasing population growth, inadequate emergency or public health responses, traditional and religious beliefs [7-13]. Notably, inadequate access to portable water and poor sanitary conditions remain the principal determinant of cholera transmission in Nigeria, in line with global epidemiology [14].

Adopting a multi-sectoral approach to cholera control and prevention is considered essential in the Global Roadmap strategies, which seek to reduce cholerarelated deaths by $90 \%$ and eliminate cholera infection in at least 20 out of the 47 endemic countries by 2030 [15]. Following the launch of the Global Roadmap strategies by the Global Task Force on Cholera Control (GTFCC) and partners in 2017, Nigeria has taken strategic steps, ranging from the implementation of oral cholera vaccination campaigns in the northern region of the country to the development of a national strategic action plan [16]. However, a major cholera outbreak across 20 states in Nigeria throughout 2018 was a reminder that the disease remains a serious public health threat. Apart from water, sanitation and hygiene (WASH) and oral cholera vaccination, the 2018 outbreak further underline the need to design and implement complementary public health interventions against recurrent cholera transmission in Nigeria; this will be informed by robust and context- specific evidence on the drivers of cholera transmission in the country. To the best of our knowledge, there is a dearth of evidence in this regard. Two previous reviews on cholera in Nigeria were focused primarily on its epidemiology (causative pathogen, history, geographical distribution, and infection pattern) [17] and description of cholera trends [18], with limited methodological robustness and potential publication bias. For example, these studies provided little or no information about how the literatures were searched and selected, and it was unclear who conducted the searches, selected the studies as well as how the data were extracted, analysed and synthesised. To this end, this study aimed to address the evidence gap in relation to the drivers of recurring cholera transmission in Nigeria and, equally important, to provide a systematic analysis of the operational dynamics of the identified drivers.

\section{Methods \\ Methodological framework}

A scoping review was adopted for this study given its flexibility to accommodate diverse study designs and its capacity to address research questions from a relatively broad perspective [19]. Specifically, we adopted the methodological framework as outlined in Arksey and O'Malley [19] guide, which identifies five iterative stages in conducting a scoping review:

- Identifying the research question(s)

- Identifying relevant studies

- Selecting the relevant studies

- Charting the data

- Collating, summarizing and reporting the research findings

Each of these stages are described below.

\section{Stage 1: identifying the research question}

The overarching research questions that guided this scoping review were: (1) what are the drivers of recurrent cholera transmission in Nigeria, and (2) what is the operational dynamics of the identified drivers relating to cholera transmission in Nigeria?

\section{Stage 2: identifying relevant studies}

We decided to use a broad definition of search terms and selection of study designs at the outset of this study in order to minimise the chances of missing relevant documents, despite the possibility of generating an enormous number of references during data search. To define the 'drivers' of cholera transmission, we adapted the definition proposed by Wepner and Giesecke [20]: developments or factors causing change in or affecting and shaping the transmission of cholera in Nigeria. Additionally, we 
purposely chose the term 'transmission' rather than 'outbreak or epidemic' in line with the broad scope of a scoping review.

Four bibliographic literature sources (CINAHL (Plus with full text), Web of Science, Google Scholar and PubMed) and one journal (African Journals Online (AJOL)) were searched to retrieve documents relating to the drivers of cholera transmission in Nigeria (see Supplementary File 1 for details). With the exception of AJOL, the need to seek breadth rather than depth in a scoping review informed the use of the following search terms in all the data sources: "Cholera" OR "Vibrio" OR "Vibrio cholerae" AND "Nigeria". However, we used the following search terms on AJOL: "Cholera" AND "Nigeria". Although we initially used a search strategy that included 'diarrhoea' and its variants, this was later refined based on early results. Furthermore, we searched other potential document sources including reference lists of selected documents for additional documents that might be useful in addressing the research questions. However, we decided at the outset not to contact experts in the field for ongoing or unpublished works due to the limited time allocated for this research. This stage of the review was undertaken from November 21st, 2018 to November 25, 2018.

\section{Stage 3: selection of relevant documents}

The following predefined eligibility criteria were used in guiding the inclusion of documents for this scoping review:

- The document had to be a peer-reviewed journal article, conference paper, book chapter, review, case study or short paper

- The document had to focus on cholera, be it in an epidemic or endemic context, in Nigeria

- The document had to include Vibrio cholerae or its abbreviation

- The document had to be written in English and published between 1970 (when cholera outbreak was first reported in Nigeria) and the period of data search (November 2018)

We excluded the following documents: editorial, letter, commentary, authored book, book review, or news items as well as documents that focused only on other Vibrio species (e.G. Vibrio parahaemolyticus and Vibrio vulnificus).

Two of the authors (KE and SO) independently applied the predefined eligibility criteria in screening the titles and abstracts of all the selected documents to identify relevance to the research questions. Additionally, the same authors independently screened the full-texts of the selected documents in order to ascertain their eligibility for study; any discrepancies between the two authors were resolved through a discussion or, where an agreement was not reached by consultation with a third author (AM).

\section{Stage 4: data charting}

Data charting or extraction describes the synthesis and interpretation of data through sifting and sorting in accordance with the common themes [21]. Thus, we developed a comprehensive provisional data extraction form using an inclusive approach, which was then reviewed by all the authors to ensure the variables were relevant. Comments and suggestions from co-authors were addressed to develop the final data extraction form (Supplementary File 2). For data entry and management, however, the data extraction form was translated from MS Word into Excel format. Two authors (KE and SO) conducted data extraction process while discrepancies were addressed using the approach outlined in the previous stage.

\section{Stage 5: collating, summarising and reporting the results}

Two sets of narrative accounts of findings were presented. The first account focused on a bibliometric analysis of the documents, with a view to understanding the nature and general information about the identified documents (e.g. study design, clinical features, location studies were undertaken etc.). The second account involved organising the documents thematically according to the identified drivers. Using Stata version 15 (StataCorp LP, College Station, TX, USA), findings of the bibliometric analysis were presented using descriptive statistics which included frequencies and percentages for binary and categorical variables, and mean (standard deviation) and median (inter-quartile range) for continuous variables with normal and non-normal distributions, respectively. Furthermore, a systematic analysis was conducted to provide an in-depth understanding of the operational dynamics (mechanism of actions) of the identified drivers. Findings from this analysis were presented using Vensim software (version PLE $\times 32$ ). As the development of reporting guidance for the conduct and reporting of scoping reviews is underway, the Preferred Reporting Items for Systematic Reviews and Meta-Analyses (PRISMA) protocols were followed in reporting our findings where appropriate [22] (see Supplementary File).

\section{Results}

\section{Description of documents}

Of the 317 documents screened for eligibility, 45 documents met the predefined inclusion criteria and formed the basis for this study (Fig. 1). The characteristics of these documents are summarised in Table 1 . The majority of the documents were peerreviewed journals $(88.89 \%)$, over half $(64.44 \%)$ were 


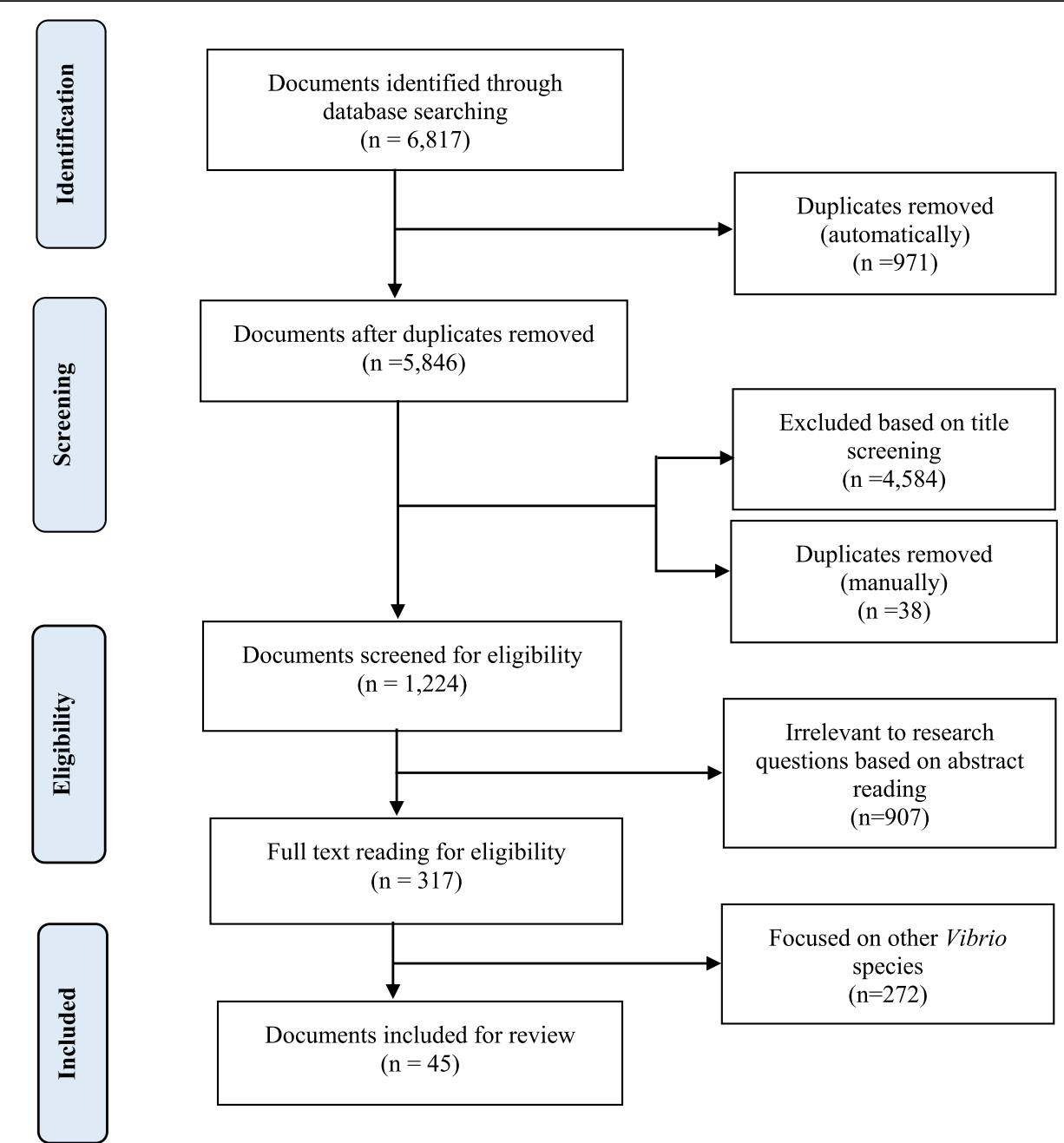

Fig. 1 A flowchart showing the selection of documents for the scoping review

published between 2011 and 2018 while only four (8.89\%) documents were published prior to 1990 . The majority (64.44\%) of the studies were undertaken in the context of cholera epidemics, and predominantly cross-sectional (62.22\%) in terms of epidemiological design. Nearly half $(48.89 \%)$ of the documents reported an average case fatality rate of $6.53 \%$. Regarding microbiological investigations, 48.49 and $11.11 \%$ of the documents conducted culture and rapid diagnostic test, respectively. Although a substantial number of documents were not specific regarding $V$. cholerae biotype, El-Tor (8.89\%) and a combination of Classical and El-Tor (4.44\%) biotypes were reported. Moreover, there were more reports of Ogawa $(17.78 \%)$ than Inaba (2.22\%) serotype, although a combination of both serotypes $(2.22 \%)$ was also reported. Fig. 2 shows the 36 states and the Federal Capital Territory in Nigeria.

\section{Thematic analysis of documents}

Five broad factors were identified as potential drivers for recurring cholera transmission in Nigeria: (1) social, (2) biological, (3) environmental and climatic, (4) health systems, and (5) multiple (a combination of two or more factors) drivers (Table 2). Over three-quarters of the documents were related to social drivers, making it the most frequently reported driver of cholera transmission. We identified 'multiple' factors as the second driver (i.e. a combination of two or more factors) while biological drivers were the least reported.

Table 3 describes the identified drivers of cholera transmission in Nigeria in detail, while citing specific examples from the reviewed documents.

\section{Social drivers of cholera transmission}

Social drivers of cholera transmission appear to be operating at two levels: micro and macro. At the micro-level, 
Table 1 Baseline characteristics of reviewed documents $(N=45)$ Characteristic Frequency (\%) General characteristics

\section{Authors' affiliation}

Academic institution

Academic and government

Academic and hospital

Academic and International NGO

Governmental health institution

Governmental health institution and International NGO

International NGO

\section{Document type}

Conference proceeding

Peer-reviewed journal

Publication period

$<1990$
$1990-2000$
$2001-2010$
$2011-2018$

State where study was undertaken

$\begin{array}{ll}\text { Akwa-lbom and Cross-River } & 1(2.22) \\ \text { Bauchi } & 1(2.22) \\ \text { Bauchi and Gombe } & 1(2.22) \\ \text { Bauchi, Borno and Gombe } & 2(4.44) \\ \text { Bauchi, Borno and Osun } & 1(2.22) \\ \text { Benue } & 1(2.22) \\ \text { Borno } & 2(4.44) \\ \text { Cross-River } & 4(8.89) \\ \text { Jigawa } & 2(4.44) \\ \text { Kaduna } & 4(8.89) \\ \text { Kano } & 2(4.44) \\ \text { Katsina } & 1(2.22) \\ \text { Lagos } & 2(4.44) \\ \text { Nasarawa } & 1(2.22) \\ \text { Niger } & 1(2.22) \\ \text { Ogun } & 1(2.22) \\ \text { Osun } & 2(4.44) \\ \text { Oyo } & 7(15.56) \\ \text { Rivers } & 1(2.22) \\ \text { Multiple states (> 3 states) } & 8(17.78)\end{array}$

\section{Study context}

Epidemic

Endemic

Endemic and epidemic

Unspecified
4 (8.89)

6 (13.33)

$6(13.33)$

$29(64.44)$

(2.22)

$(2.22)$

$(2.22)$

(4.44)

$(2.22)$

$(2.22)$

(4.44)

(8.89)

$(4.44)$

(8.89)

(4.44)

(2.22)

(4.44)

(2.22)

(2.22)

(2.22)

(4.44)

(15.56)

(17.78)

$29(64.44)$

9 (20.00)

$6(13.33)$

$1(2.22)$

Table 1 Baseline characteristics of reviewed documents $(N=45)$ (Continued)

\begin{tabular}{ll}
\hline Characteristic & Frequency (\%) \\
\hline Study approach & \\
Prospective & $18(40.00)$ \\
Retrospective & $23(51.11)$ \\
Prospective and retrospective & $3(6.67)$ \\
Unclear & $1(2.22)$ \\
Study design & \\
Case-control & $10(22.22)$ \\
Cross-sectional & $28(62.22)$ \\
Review & $4(8.89)$ \\
Unspecified & $3(6.67)$ \\
Median sample size reported in & $329(109-1220)$
\end{tabular}
documents (IQR)

Age group of study participants

All age groups

17 (37.78)

Adults

$2(4.44)$

Children under-5 years

$1(2.22)$

Children under-14 years

$1(2.22)$

Unspecified

$24(53.33)$

Funding for study

Unspecified

$41(91.11)$

Yes

$4(8.89)$

Ethical approval for the study

Unspecified

$34(75.56)$

Yes

$11(24.44)$

Clinical characteristics

Data collection approach

Record extraction

$4(8.89)$

Microbiological examination

7 (15.56)

Questionnaire

$9(20.00)$

Record extraction and microbiological

1 (2.22)

examination

Questionnaire and microbiological

$9(20.00)$

examination

Record extraction and questionnaire

$2(4.44)$

Record extraction, questionnaire and microbiological examination

$1(2.22)$

Record extraction, questionnaire and

$2(4.44)$

observation

Unspecified

$10(22.22)$

Report of case fatality rate (\%)

No

$23(51.11)$

Yes

$22(48.89)$

Mean (SD) case fatality rate 
Table 1 Baseline characteristics of reviewed documents $(N=45)$ (Continued)

\begin{tabular}{|c|c|}
\hline Characteristic & Frequency (\%) \\
\hline \multicolumn{2}{|l|}{ Report of attack rate } \\
\hline No & $40(88.89)$ \\
\hline Yes & $5(11.11)$ \\
\hline \multicolumn{2}{|c|}{ Location of sample collection } \\
\hline Community & $11(24.44)$ \\
\hline IDP camp & $1(2.22)$ \\
\hline Primary & $1(2.22)$ \\
\hline Secondary & $1(2.22)$ \\
\hline Tertiary & $4(8.89)$ \\
\hline Primary and secondary & $1(2.22)$ \\
\hline Secondary and tertiary & $3(6.67)$ \\
\hline Tertiary and private & $1(2.22)$ \\
\hline Unspecified health facility & $2(4.44)$ \\
\hline $\begin{array}{l}\text { Unspecified health facility } \\
\text { and community }\end{array}$ & $4(8.89)$ \\
\hline $\begin{array}{l}\text { Unspecified health facility } \\
\text { and IDP camp }\end{array}$ & $1(2.22)$ \\
\hline Unspecified & 15 (33.33) \\
\hline \multicolumn{2}{|l|}{ Culture } \\
\hline No & $11(24.44)$ \\
\hline Yes & $22(48.89)$ \\
\hline Unspecified & $12(26.67)$ \\
\hline \multicolumn{2}{|c|}{ Rapid diagnostic test performed } \\
\hline No & $40(88.89)$ \\
\hline Yes & $5(11.11)$ \\
\hline \multicolumn{2}{|l|}{ Identified biotype } \\
\hline Classical & $1(2.22)$ \\
\hline El-Tor & $4(8.89)$ \\
\hline Classical \& El-Tor & $2(4.44)$ \\
\hline Atypical El-Tor & $1(2.22)$ \\
\hline Unspecified & $37(82.22)$ \\
\hline \multicolumn{2}{|l|}{ Identified serogroup } \\
\hline 01 & $13(28.89)$ \\
\hline Non-O1 & $2(4.44)$ \\
\hline Unspecified & $30(66.67)$ \\
\hline \multicolumn{2}{|l|}{ Identified serotype } \\
\hline Ogawa & 8 (17.78) \\
\hline Inaba & $1(2.22)$ \\
\hline Ogawa and Inaba & $1(2.22)$ \\
\hline Unspecified & 35 (77.78) \\
\hline
\end{tabular}

a Based on 34 out of 45 documents

based on 22 out of 45 documents social drivers are either operating at the household- or individual-level. However, the majority of social drivers at the household-level seem to drive cholera transmission indirectly through the enforcement of other drivers. For instance, a large household size drives cholera transmission indirectly by creating an over-crowded environment, thereby enhancing the likelihood of a personperson transmission of cholera via a common source, such as contaminated water or food. It is worth noting that social drivers operating at the individual-level tend to be behavioral- or cultural-related, such as open defecation. Social drivers operating at the macro-level appear to drive cholera transmission through governmental or political actions and inactions as opposed to individual and household drivers. Although driving cholera transmission indirectly, these social drivers have the capacity to cause a widespread cholera outbreak. Availability of portable water is fundamental to cholera prevention and control, but is often dependent on constant power supply for functionality. Moreover, trade and migration exert their influence on cholera transmission in a similar manner; and armed-conflicts and terrorism, especially that which is perpetuated by Boko Haram terrorist group in the north-east region of the country, drives cholera transmission indirectly by creating enabling conditions, such as including over-crowdedness, disruption of clean water, exacerbation of malnutrition, and among many others.

\section{Biological drivers of cholera transmission}

Biologically, recurrent cholera transmission appears to be driven by genetic mutation and the resulting acquisition of resistant genes and changes in major virulence determinant genes by $V$. cholerae. In addition, the role of biological drivers appears to be dependent, partly, on the activities of certain social drivers operating at the individual level (e.g. poor attitude towards cholera infection and treatment).

\section{Environmental and climatic drivers of cholera transmission}

Environmental drivers pertain to natural disasters, such as flooding, or human-made events, such as water source contamination. Natural disasters appear to operate at the macro-level and drive cholera transmission indirectly by creating an enabling environment for $V$. cholera proliferation or, by enforcing other drivers. In contrast, environmental drivers of human-made events or anthropogenic activities tend to drive cholera transmission directly by serving as a reservoir or a transmission media (e.g. open-wells) for the causative organism $V$. cholerae. With respect to climatic drivers, rainfall and temperature are the predominant factors and seem to drive cholera transmission indirectly; for instance, 


\section{Map of Nigeria}

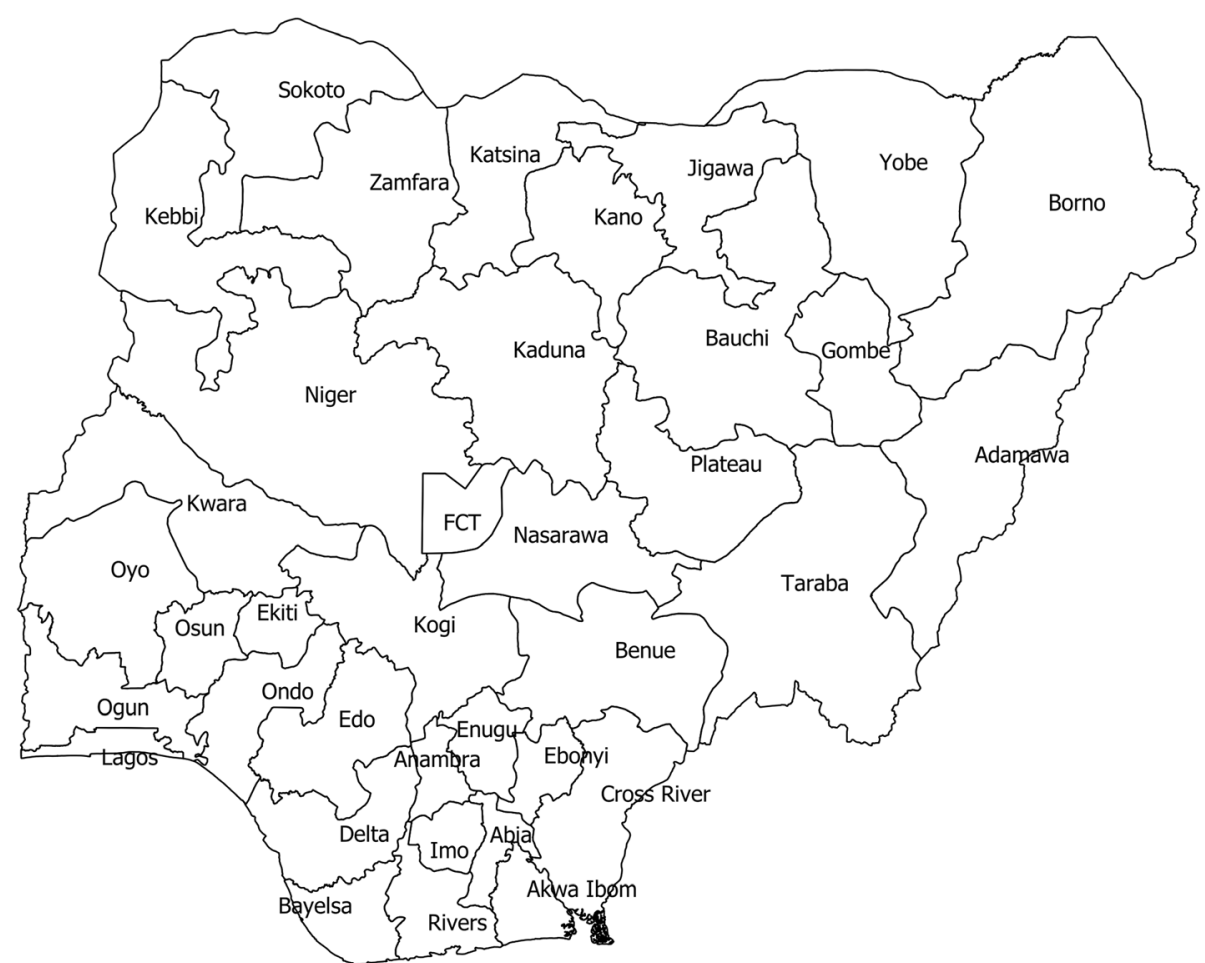

Fig. 2 A map of Nigeria showing the 36 states and Federal Capital Territory. Source: Risk Communication Unit of the Nigeria Centre for Disease Control; developed using ArcGIS software version 10.7

through the genetic mutation of $V$. cholerae due to changing environmental levels of temperature).

\section{Health systems-related drivers of cholera transmission}

Health systems-related drivers were found to be operating primarily in three areas: health provision by health professionals, health seeking by community members, and interphase between health provision and health seeking. Essential to health provision is a relatively fragile surveillance system that is enforced by inadequate funding and training of health professionals as well as limited capacity for cholera diagnosis and case notifications. In contrast, health seeking within the community tends to drive cholera transmission largely due to individual characteristics including inadequate knowledge and inappropriate attitude and practices towards cholera. Interestingly, although implicitly stated in the relevant documents, certain health-related drivers of cholera transmission in Nigeria operate at the interphase between healthcare provision and healthcare seeking. An example depicting this scenario is the lack of community trust for a surveillance system and formal health care facilities, which could be instigated by poor attitudes of health workers to patients.

\section{Multiple drivers of cholera transmission}

Apart from social drivers with the highest frequency of citations, most of the reviewed documents are centred upon at least two drivers (multiple drivers) of recurring cholera transmission concurrently. For instance, over-

Table 2 Distribution of the drivers of cholera transmission in Nigeria, $N=45$

\begin{tabular}{ll}
\hline Driver & Citation frequency of the reviewed documents \\
\hline Social (demographic, cultural and economic) & 35 \\
Biological (host and genetics) & 3 \\
Environmental and climatic & 11 \\
Health systems-related & 8 \\
Multiple $^{\text {a }}$ & 27
\end{tabular}

${ }^{a}$ Climatic and social drivers $(n=2)$; social and biological drivers $(n=3)$; social and health systems-related drivers $(n=1)$; and two or more drivers $(n=21)$ 
Table 3 A description of the drivers of cholera transmission in Nigeria

\begin{tabular}{|c|c|c|}
\hline Cholera transmission driver & Level/category & Examples from the reviewed documents \\
\hline \multirow[t]{8}{*}{ Social } & Micro-level & \\
\hline & • Household & $\begin{array}{l}\text { - Large household size and over-crowdedness } \\
\text { - Poor sanitation and hygiene practices } \\
\text { - Poor sewage disposal practices } \\
\text { - Socioeconomic status (income and/or education) } \\
\text { - Inter-family transmission/contact } \\
\text { - Reliance on contaminated water sources (e.g. open wells) }\end{array}$ \\
\hline & Micro-level & \\
\hline & - Individual & $\begin{array}{l}\text { - Open defecation } \\
\text { - Consumption of seafood, sea and estuarine waters } \\
\text { - Inadequate knowledge, and poor attitude and practices towards cholera } \\
\text { - Religious beliefs (e.g. reluctance among female patients to seek care from } \\
\text { male-dominated health providers) } \\
\text { - Superstitious beliefs and/or myths }\end{array}$ \\
\hline & Macro-level & \\
\hline & - Governance/political & $\begin{array}{l}\text {-Water scarcity due to inadequate power supply (electricity) } \\
\text { - Inadequate public water supply }\end{array}$ \\
\hline & Macro-level & \\
\hline & - Trade and migration & $\begin{array}{l}\text { - Increased fishing activities (e.g. trade traffic on the Calabar river estuary) } \\
\text { - Increased migration and internal displacement of people (primarily due to } \\
\text { armed conflicts) }\end{array}$ \\
\hline Biological & Genetics & $\begin{array}{l}\text { - Acquisition of resistance genes } \\
\text { - Changes in the major virulence determinant genes }\end{array}$ \\
\hline \multirow[t]{5}{*}{ Environmental and climatic } & Environmental & \\
\hline & - Natural disaster & • Flooding \\
\hline & Environmental & \\
\hline & - Human-made & $\begin{array}{l}\text { - Contaminated water sources by poor sewage disposal, waste dumps, abattoir, } \\
\text { among others. } \\
\text { - Street-vended and sachet water }\end{array}$ \\
\hline & Climatic & - Unfavourable weather variables including rainfall and temperature \\
\hline \multirow[t]{3}{*}{ Health systems-related } & Health provision & $\begin{array}{l}\text { - Inadequate funding for surveillance system } \\
\text { - Inadequate training of health workers and health facilities } \\
\text { - Inadequate supply of essential materials including oral cholera vaccine and } \\
\text { oral rehydration solutions } \\
\text { - Limited capacity for prompt and accurate cholera diagnosis, and delays in the } \\
\text { notification of cholera cases }\end{array}$ \\
\hline & Health seeking & $\begin{array}{l}\text { - Delay in seeking care at formal health facilities after cholera onset } \\
\text { - Inadequate knowledge, attitude and practices towards cholera } \\
\text { - }\end{array}$ \\
\hline & $\begin{array}{l}\text { Interphase between health } \\
\text { provision and seeking }\end{array}$ & $\begin{array}{l}\text { - Lack of trust by community members for formal health systems } \\
\text { - Religious and/or superstitious beliefs }\end{array}$ \\
\hline Multiple & $\begin{array}{l}\text { A combination of two or } \\
\text { more drivers }\end{array}$ & $\begin{array}{l}\text { - Over-crowdedness due to increasing population and natural disasters and } \\
\text { human-made factors (e.g. conflicts) } \\
\text { - Fragile surveillance system and limited political-will }\end{array}$ \\
\hline
\end{tabular}

crowding which increases the risk of cholera transmission was found to result from increased influx of a displaced population into a community due to either a natural disaster (e.g. flooding) or armed conflict (i.e. a social driver operating at the macro-level).

\section{Dynamics of the drivers of cholera transmission in Nigeria} Figure 3 below depicts the operational dynamics of the identified drivers of cholera transmission in the Nigerian context. The majority of the drivers of cholera transmission are interdependent of each other, such that they are either enforcing the activities of other drivers or their activities are being enforced by others to bring about cholera transmission. For instance, religious and superstitious beliefs (lower left of Fig. 3) could influence or be influenced by community knowledge, attitude and practices towards cholera, as well as community trust for health system and delay in seeking health care following symptom onset. 


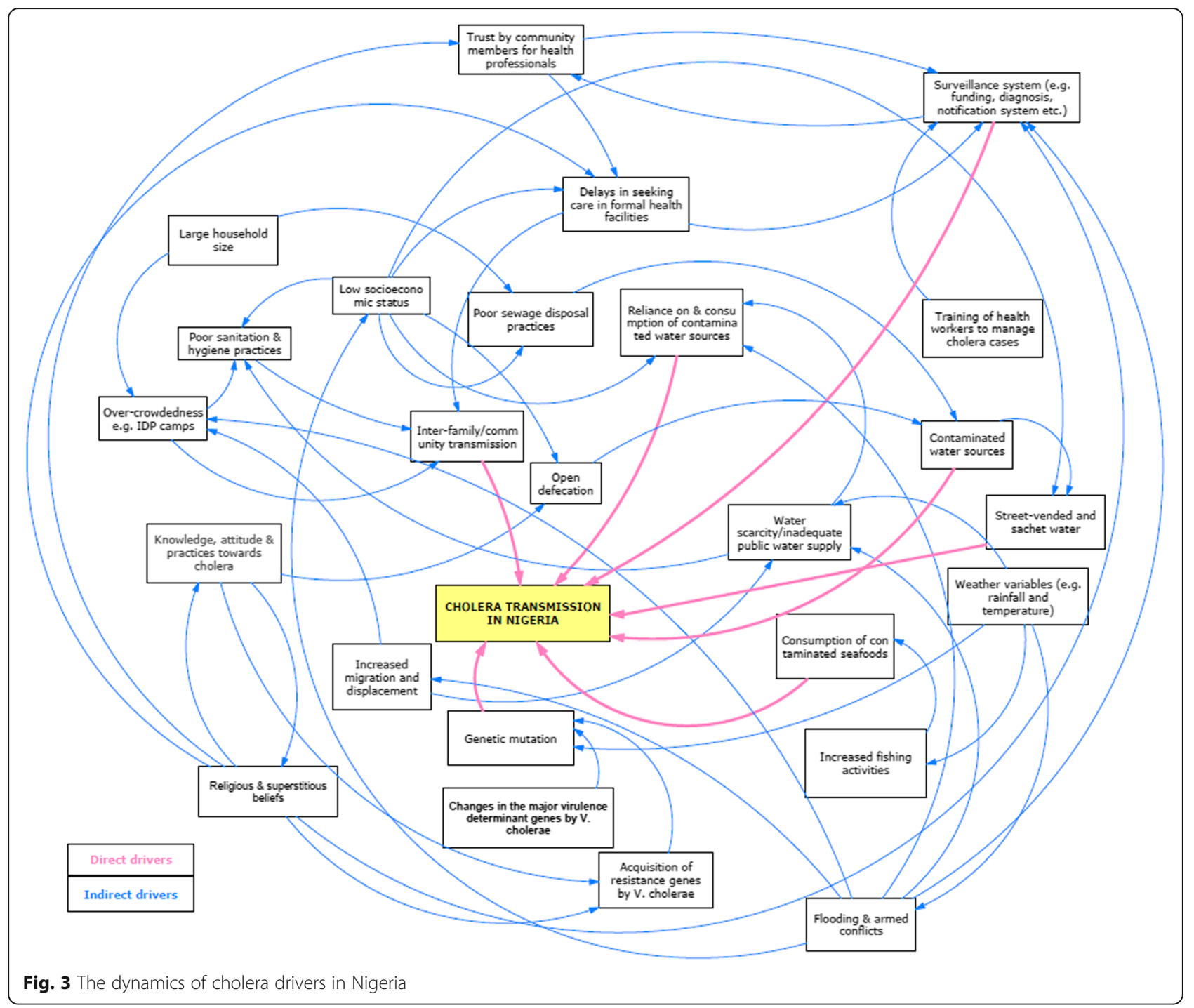

Overall, the majority of the drivers of recurrent transmission of cholera in Nigeria seem to be intertwined rather than operating in isolation.

\section{Discussion}

\section{Summary of key findings}

The findings from this scoping review are timely given the global urgency to address recurring cholera outbreaks, especially in countries with high attack and case fatality rates. Overall, this study has identified the drivers of recurrent cholera transmission in Nigeria. The identified drivers pertained to a combination of social, biological, environmental and climatic, and health systems-related factors.

\section{Interpretation of key findings}

A majority of the reviewed documents [7, 13, 17, 23-50] pertained to social drivers. Notably, the significant impact of cultural and behavioural factors on individual social drivers of cholera transmission (e.g. open defecation, food consumption among others) was noted, as well as the prominence of religious, superstitious and traditional beliefs in Nigeria [51, 52]. This study has therefore underlined the need to address erroneous socio-cultural beliefs, especially in rural areas, in ongoing efforts to mitigate cholera transmission. Open defecation is a prevalent practice in many areas of Nigeria, as indicated by a recent ranking in which the country was ranked third after India and China [53]. Individual-based approach to reverse this harmful practice in Nigeria has been demonstrated to be ineffective [54], thus necessitating the importance of adopting a multi-sectoral approach to designing preventive measures against this harmful practice. The potential impact of increasing armed-conflicts on recurrent cholera transmission is not unique to Nigeria alone but is a universal phenomenon [17], as evidenced by studies in Yemen [55] and Kenya 
[56]. Although conflict resolution is not the mandates of national public health institutions, such as the Nigeria Centre for Disease Control, findings from this study indicate that interactions and collaborations among the public health, security, community and religious sectors are imperative to addressing the impact of armedconflict on recurrent cholera transmission.

The mechanism by which biological factors drive cholera transmission appears to be largely genetic-based, as opined by Adewale et al. [57], Marin et al. [58], and Oyedeji et al. [42]. Generally, genetic mutation has been demonstrated to be linked with the emergence of new, virulent and drugresistant strains of $V$. cholerae [3]. For example, Hu et al. [59] argue that the seventh cholera pandemic became prominent in 1961 after $V$. cholerae underwent series of mutations, with suitable niches in the Middle East and gene sources from Makassar to aid the genetic events. This hypothesis is supported by Marin et al. [58] wherein the 2009 and 2010 cholera outbreaks in Nigeria were linked to multidrug resistant atypical El Tor strains. Further supporting this evidence are findings in India [60] and Mozambique [61]. In practice, continuous surveillance of antibiotic resistance by public health institutions will be critical for mitigating cholera transmission in Nigeria.

Rainfall $[7,26,30,32,45,62]$ and temperature $[7,26,50]$ were identified as primary climatic drivers of cholera transmission in Nigeria. The association between cholera outbreaks and climatic drivers, particularly seasonal tropical rainfall, is well documented in other contexts [63-66]. Two mechanistic models for cholera transmission with respect to rainfall have been proposed: cholera transmission tends to be enhanced given the high tendency for consumption of contaminated water and worsening sanitary conditions from floods; and the ease with which water becomes contaminated by freshly excreted bacteria resulting from washout of open-air defecation sites, or overflows from pit latrines during and after rainfall. These models have been validated in South Sudan [67] and Senegal [68]. A 2-fold increase in cholera cases with a $1{ }^{\circ} \mathrm{C}$ increase in temperature at 4 months lag has been reported in Zanzibar [69], indicating the importance of temperature in cholera transmission. Flooding was also identified as an environmental driver of cholera transmission in Nigeria [41, 70]. Flooding increases cholera transmission by (1) disrupting access to or contaminating safe water sources; (2) affecting sanitation conditions; and (3) limiting access to essential health services [71-73]. Although we did not identify studies that specifically explored the association between droughts and increased cholera transmission in Nigeria, evidence [74] suggests that the two variables are significantly linked.

Eight studies [12, 17, 24, 32, 41, 50, 70, 75] found the potential role of health systems-related factors in driving the transmission of cholera in Nigeria. Regarding health service delivery, evidence centred on inadequate and inefficient surveillance system, as well as inadequate laboratory diagnostic capacity; in addition, poor technical capacity of health workers to manage cholera cases, especially in rural areas. In rural areas in Nigeria, it is not surprising to encounter health workers with inadequate training on cholera case management, as well as with inadequate supply of emergency response kits [12]. From the perspective of health care seeking by community members, religious and traditional beliefs play a significant role in driving cholera transmission. The effect of erroneous beliefs-e.g. cholera is caused by an evil spirit (or apparition) or "it's Gods' will"-on cholera transmission however appears to be indirect by hindering health care seeking following cholera infection. Such beliefs have also been linked with poor outcomes of control and prevention interventions in endemic areas of West Africa [13]. This evidence further reiterates the need for actively engaging both community and religious stakeholders in the fight against cholera in Nigeria and, perhaps, in other endemic countries with similar socio-cultural profile.

Twenty-seven documents captured multiple drivers of cholera transmission in Nigeria, underlining the interdependency of the identified drivers and a need for an 'allinclusive' or a multi-sectoral control and prevention strategy. This approach is being advocated by the Global Task Force on Cholera Control (GTFCC) and partners for cholera control worldwide [15]. Importantly, this evidence suggests that improving access to WASH services and provision of oral cholera vaccines alone might not be sufficient to yield the desired goals, as stipulated in the GTFCC Global Roadmap strategic goals. That is, there should be a balance between investment in preventive and control measures and the recipient community in order to ensure adherence and wider uptake during a cholera outbreak [76].

\section{Strengths and limitations}

This study has the advantage of adopting a robust methodological framework with a number of shared processes with systematic reviews, and less prone to publication bias given the emphasis on breadth (covering all available material) over depth (providing a detailed analysis and appraisal of a smaller number of studies) [19]. However, some limitations associated with this study are worth acknowledging. Firstly, unlike systematic reviews, the quality of evidence in the reviewed documents was not formally appraised. Although the primary focus of a scoping review is addressing study specific questions rather than quality assessment [19], the preponderance of cross-sectional studies, with limited capacity to establish causality, needs to be considered in interpretation of our findings. Secondly, the adopted framework for a scoping review does not allow for synthesis, suggesting that only narrative or descriptive account of evidence could be achieved. However, we conducted an in-depth analysis 
of the operational dynamics of the identified drivers. An optional stage in the adopted framework for a scoping review is a 'consultation exercise' whereby the views of practitioners and experts in a field are sought in order to provide additional references about the subject of discussion that the review alone would not have identified. In addition to resource implications of implementing this step, the current research team members, many of whom are experts in the field, however provided inputs in synthesising the operational dynamics of cholera drivers.

\section{Conclusion}

These findings from this scoping review indicate that the drivers of recurring cholera transmission in Nigeria are diverse but functionally interdependent, underlining the importance of a multi-sectoral approach towards cholera prevention and control.

\section{Supplementary information}

Supplementary information accompanies this paper at https://doi.org/10. 1186/s12889-020-08521-y.

Additional file 1.

Additional file 2.

Additional file 3.

\section{Abbreviations}

PRISMA: The Preferred Reporting Items for Systematic Reviews and MetaAnalyses; WASH: Water, Sanitation and Hygiene

\section{Acknowledgements}

Not applicable.

\section{Authors' contributions}

KOE Conceptualization, literature search, screening, analysis, writing and formatting of document. SM Literature screening, analysis, and writing (original draft, review and editing). AM Literature screening, analysis, and writing (review and editing). OO Literature screening and writing (original draft, review and editing). ISF Conceptualisation, writing (review and editing), and funding acquisition. SY Literature acquisition, software, and writing (review and editing). MY Conceptualisation, software, and writing (review and editing). POA Conceptualisation, writing (review and editing), and funding acquisition. NW Data acquisition and writing (review and editing). LHO Conceptualisation, writing (review and editing), and funding acquisition. TB Conceptualisation, writing (review and editing), and funding acquisition. KA Data acquisition and writing (review and editing). IO Project administration, supervision and writing (review and editing). LI Project administration, writing (review and editing) and software. AJ Data acquisition, project administration, and writing (review and editing). WA Conceptualization, supervision, and writing (review and editing). CP Conceptualization, supervision, writing (review and editing), funding acquisition, project administration, and resources. Cl Conceptualization, supervision, writing (review and editing), funding acquisition, project administration, and resources. All authors read and approved the final manuscript.

\section{Authors' information}

KOE, PhD: Has a background in applied epidemiology, systems strengthening, and medical microbiology.

SM MSc: Has a background in medical microbiology and immunology. AM, PhD: Has a background in applied statistics, epidemiology and geographical information system.
OO, BSC: Has a background in microbiology and public health management. ISF, PhD: Has a background in outbreak response and public health management.

SY, MSC: Has a background in cholera outbreak response having worked as the country incident manager for a substantial period.

MY, MSc: Has a background in cholera management both in the context of outbreak response and routine surveillance.

$\mathrm{PA}, \mathrm{MPH}$ : Has a background in cholera management both in the context of outbreak response and routine surveillance.

NW, BSc: Currently serves as the deputy cholera lead in Nigeria and often engage in outbreak coordination activities across the country.

LHO, MSc: Has a background in cholera management both in the context of outbreak response and routine surveillance.

TB, PhD: Has a background in cholera management both in the context of outbreak response and routine surveillance.

KA, PhD: Has a background in cholera management both in the context of outbreak response and routine surveillance.

IO, MPH: Currently supports cholera (and other infectious disease) outbreak coordination as well as policy development.

$\mathrm{LI}, \mathrm{MPH}$ : Has a background in cholera management both in the context of outbreak response and routine surveillance.

AJ, MPH: Has extensive experience in cholera management, and currently supports leadership-related activities at the NCDC Director General's office. WA, MPH: Formerly the WHO country director with substantial experience in the coordination of cholera outbreak response. He was very helpful in drafting the manuscript with practical insights in discussing the findings. $\mathrm{CP}, \mathrm{MPH}$ : Currently the WHO director in Nigeria and formerly the country director in Liberia. He provided valuable insights as how cholera drivers might be operating both at the national and local levels, as well as drafting the manuscript.

Cl, MD: Currently the Director General of NCDC. He provided valuable insights as how cholera drivers might be operating both at the national and local levels, as well as drafting the manuscript.

\section{Funding}

World Health Organization provided a consultancy fee to the lead author (KOE) through the Nigerian office; however, WHO played no role in the study design, data collection and analysis, decision to publish, or preparation of this manuscript.

\section{Availability of data and materials}

The documents used for this study are available upon request to the corresponding author.

Ethics approval and consent to participate Not applicable.

\section{Consent for publication}

Not applicable.

\section{Competing interests}

The authors declare that they have no competing interests.

\section{Author details}

${ }^{1}$ Nigeria Centre for Disease Control, Abuja, Nigeria. ${ }^{2}$ University of Benin, Benin, Nigeria. ${ }^{3}$ University College London, London, UK. ${ }^{4}$ World Health Organization, Regional Office for Africa, Brazzaville, Republic of Congo.

${ }^{5}$ World Health Organization, Abuja, Nigeria.

Received: 10 May 2019 Accepted: 12 March 2020

Published online: 03 April 2020

\section{References}

1. Clemens JD, Nair GB, Ahmed T, Qadri F, Holmgren J. Cholera. Lancet. 2017; 390:1539-49.

2. Microbiology Society. Factfile: cholera: death by diarrhoea. 2016.

3. Sharmila T, Thomas TA. Pathogenesis of Cholera: Recent Prospectives in Rapid Detection and Prevention of Cholera; 2016. p. 129-44.

4. Ali M, Nelson AR, Lopez AL, Sack DA. Updated global burden of cholera in endemic countries. PLoS Negl Trop Dis. 2015;9:e0003832.[2019 Jun 11]Public Library of Science. 
5. World Health Organization. Number of reported cholera cases: WHO. Geneva: World Health Organization; 2017.

6. World Health Organization. Cholera: Key Facts. Geneva: WHO; 2019.

7. Babatimehin O, Uyeh J, Onukogu A. Analysis of the re-emergence and occurrence of cholera in Lagos state, Nigeria. In: Chodkowska-Miszczuk J, Szymańska D, editors. Bull Geogr. Toruń: Nicolaus Copernicus University; 2017. p. 21-32.

8. Legros D, Partners of the Global Task Force on cholera control. Global cholera epidemiology: opportunities to reduce the burden of cholera by 2030. J infect dis Oxford University Press. 2018;218:S137-40

9. Auwal F. Potential Future Risk of Cholera Due to Climate Change in Northern Nigeria, vol. 11; 2017. p. 205-18.

10. Leckebusch GC, Abdussalam AF. Health \& Place Climate and socioeconomic in $\mathrm{fl}$ uences on interannual variability of cholera in Nigeria, vol. 34; 2015. p. $107-17$

11. Nuhu A, Yusuf KM. The Effect of Religious Conflicts in Northern Nigeria on Public Health Outcomes : A Case Study of Cholera Outbreak, vol. 14; 2018. p. 408-18.

12. Oladele DA, Oyedeji KS, Niemogha M-T, Nwaokorie F, Bamidele M, Musa AZ, et al. An assessment of the emergency response among health workers involved in the 2010 cholera outbreak in northern Nigeria. J Infect Public Health Elsevier. 2012;5:346-53.

13. Ujah I, Nwaokorie F, Adeneye A, Oladele D, Bamidele T, Musa S, et al. A review of perception and myth on causes of cholera infection in endemic areas of Nigeria. Afr J Microbiol Res. 2015;9:557-64.

14. Impouma B, Kasolo F, Yada A, Yoti Z, Yaya S, Woodfill C, et al. Recurring epidemics in the WHO African region: situation analysis, preparedness and response. Afr Health Monit. 2012;(2).

15. Global Task Force on Cholera Control. Ending Cholera: A Global Roadmap to 2030. Annecy: World Health Organization (WHO); 2017. p. 32.

16. Nigeria Centre for Disease Control. National Strategic Plan of Action on Cholera Control. Abuja: Nigeria Centre for Disease Control (NCDC); 2019.

17. Adagbada AO, Adesida SA, Nwaokorie FO, Niemogha M-T, Coker AO. Cholera epidemiology in Nigeria: an overview. Pan Afr Med J African Field Epidemiology Network. 2012;12:59 [2018 Nov 19].

18. Aminu M, Medugu J. Increased cholera outbreaks in Nigeria: a review. East London, East Cape, South Africa. Eastern Cape, South Africa: Proc 4th Walter Sisulu Univ Int Res Conf; 2011. p. 47-64.

19. Arksey H, O'Malley L. Scoping studies: towards a methodological framework. Int J Soc Res Methodol. 2005;8:19-32.

20. Wepner B, Giesecke $S$. Drivers, trends and scenarios for the future of health in Europe. Impressions from the FRESHER project. Eur J Futur Res Springer Berlin Heidelberg. 2018;6:2.

21. Ritchie J, Spencer L. Qualitative data analysis for applied policy research. In: Huberman M, Miles M, editors. Qual res companion. London: SAGE Publications, Inc; 1994. p. 305-29.

22. Moher D, Liberati A, Tetzlaff J, Altman DG, PRISMA Group TP. Preferred reporting items for systematic reviews and meta-analyses: the PRISMA statement. Public Libr Sci. 2009;6:e1000097.

23. Oloruntoba EO, Folarin TB, Ayede Al. Hygiene and sanitation risk factors of diarrhoeal disease among under-five children in Ibadan, Nigeria. Afr Health Sci. 2014;14:1001-11.

24. Okeke IN, Abudu A-B, Lamikanra A. Microbiological investigation of an outbreak of acute gastroenteritis in Niger State, Nigeria. Clin Microbiol Infect. 2001;7:514-6.

25. Shittu OB, Akpan I, Popoola TOS, Oyedepo JA, Ogunshola EO. Epidemiological features of a GIS-supported investigation of cholera outbreak in Abeokuta, Nigeria. J Public Heal Epidemiol. 2010;2:152-62.

26. Abdussalam A, Thornes J, Leckebusch G, The role of climate and socioeconomic factors on the spatiotemporal variability of cholera in Nigeria, EGU Gen Assem 2015, Vienna, 2015. 2015.held 12-17.

27. Ibrahim BS, Mohammed Y, Usman R, Okon UA, Katchy UI, Olufemi AA, et al. Outbreak of cholera at Dutsen-Abba Ward Zaria local government area, Kaduna state Nigeria 2015: the importance of hygienic practices. Int J Community Med Public Heal. 2017:4:1473.

28. Ndon JA, Udo SM, Wehrenberg WB. Vibrio-associated gastroenteritis in the lower Cross-River Basin of Nigeria. J Clin Microbiol. 1992;30:2730-2.

29. Eko FO, Udo SM, Antia-Obong OE. Epidemiology and spectrum of vibrio diarrheas in the lower cross river basin of Nigeria. Cent Eur J Public Health. 1994;2:37-41.
30. Oguntoke O, Aboderin OJ, Bankole AM. Association of water-borne diseases morbidity pattern and water quality in parts of Ibadan City, Nigeria. Tanzan $J$ Health Res. 2009;11:189-95.

31. Gidado S, Awosanya E, Haladu S, Ayanleke H, Idris S, Mamuda I, et al. Cholera outbreak in a naive rural community in northern Nigeria: the importance of hand washing with soap, September 2010. Pan Afr Med J. 2018;30:5.

32. Lawoyin TO, Ogunbodede NA, Olumide EAA, Onadeko MO. Outbreak of cholera in Ibadan, Nigeria. Eur J Epidemiol. 1999;15:367-70.

33. Adeneye A, Musa A, Oyedeji R, Oladele D, Ochoga M, Akinsinde K, et al. Risk factors associated with cholera outbreak in Bauchi and Gombe states in north East Nigeria. J Public Heal Epidemiol. 2016;8:286-96.

34. Udonwa NE, Udoh SM, Ikpeme B, Andy I. Intra-family transmission of Vibrio cholerae during a cholera epidemic in rural South-Southern Nigeria. Trop Dr. 2008:38:179-80.

35. Hutin Y, Luby S, Paquet C. A large cholera outbreak in Kano City, Nigeria: the importance of hand washing with soap and the danger of streetvended water. J Water Health. 2003:1:45-52.

36. Ishaku A, Shadrack B, Ajumobi O, Olayinka A, Nguku P. Investigation of cholera outbreak in an Urban north central Nigerian community-the Akwanga experience. Public Heal Res. 2014;4:7-12.

37. Chigbu LN, Iroegbu CU. Vibrio species from diarrhoeal stools and water environment in Cross River state, Nigeria. Int J Environ Health Res. 2000;10: 219-28.

38. Fatiregun AA, Ajayi IO, Isere EE. Cholera outbreak in a southwest community of Nigeria: investigation of risk factors and evaluation of a district surveillance system. West Afr J Med. 2013;32:173-9.

39. Kolo P, Jibrin Y, Sanya E, Alkali M, Salami A, Omotoso A, et al. Outcome of cholera admissions in Bauchi, Nigeria. South African J Epidemiol Infect. 2013:28:143-6.

40. Abubakar AT, Dalhat M, Nguku P. Cholera outbreak - IDP camps in Maiduguri, northern Nigeria, September 2015. Int J Infect Dis. 2016;45:132.

41. Dalhat MM, Isa AN, Nguku P, Nasir S-G, Urban K, Abdulaziz M, et al. Descriptive characterization of the 2010 cholera outbreak in Nigeria. BMC Public Health. 2014;14:1167.

42. Oyedeji KS, Niemogha M-T, Nwaokorie FO, Bamidele TA, Ochoga M, Akinsinde KA, et al. Molecular characterization of the circulating strains of Vibrio cholerae during 2010 cholera outbreak in Nigeria. J Health Popul Nutr BioMed Central. 2013;31:178-84.

43. Umoh JU, Adesiyun AA, Adekeye JO, Nadarajah M. Epidemiological features of an outbreak of gastroenteritis/cholera in Katsina, northern Nigeria. J Hyg (Lond). 1983;91:101-11.

44. Ayeni A. Domestic water source, sanitation and high risk of bacteriological diseases in the Urban slum: case of cholera in Makoko, Lagos, Nigeria. J Environ Pollut Hum Heal. 2014;2:12-5.

45. Hunponu-Wusu OO. Epidemiological aspects of an El Tor cholera outbreak in Kaduna, Nigeria. Trop Geogr Med. 1973;25:277-81.

46. Sule IB, Yahaya M, Aisha AA, Zainab AD, Ummulkhulthum B, Nguku P. Descriptive epidemiology of a cholera outbreak in Kaduna State, Northwest Nigeria, 2014. Pan Afr Med J. 2017;27:172.

47. Nnaji RN, Ajumobi O, Bala U, Oladimeji A, Sarki M, Usman R, et al. Cholera outbreak investigation, Gajala community, Birnin kudu local government area (LGA), Jigawa state, Nigeria, September 2015. Int J Infect Dis. 2016;45: 144-5.

48. Ogbeyi O, Bito T, Anefu G, Igwe G. Determinants of knowledge, attitude and preventive practices relating to cholera in Wadata-a sub-urban slum of Makurdi, Benue state, north Central Nigeria. Int Res J Public Environ Heal. 2017:4:277-82.

49. Nuhu A, Yusuf KM, Yusuf KM. The Effect of Religious Conflicts in Northern Nigeria on Public Health Outcomes: A Case Study of Cholera Outbreak. Eur Sci J. 2018;14:408.

50. Utsalo SJ, Eko FO, Antia-Obong EO. Features of cholera and Vibrio parahaemolyticus diarrhoea endemicity in Calabar, Nigeria. Eur J Epidemiol. 1992;8:856-60.

51. Takim AO, David GI, Pefun JN. African cultural practices and health implications for Nigeria rural development. Int Rev Manag Bus Res. 2013;2: $176-83$.

52. Chiwuzie J, Okolocha C. Traditional belief systems and maternal mortality in a semi-Urban Community in southern Nigeria. Afr J Reprod Health. 2001;5: $75-82$.

53. World Bank. World development indicators 2016: featuring the sustainable development goals. Washington: World Bank; 2016. 
54. Institute of Development Studies. Community-Led Total Sanitation. 2015.

55. Dureab F, Shibib K, Al-Yousufi, Yemen JR. Cholera outbreak and the ongoing armed conflict. J Infect Dev Ctries. 2018;12:397-403.

56. Shikanga OO-T, Mutonga D, Abade M, Amwayi S, Ope M, Limo H, et al. High mortality in a cholera outbreak in Western Kenya after post-election violence in 2008. Am J Trop Med Hyg. 2009:81:1085-90.

57. Adewale AK, Pazhani GP, Abiodun IB, Afolabi O, Kolawole OD, Mukhopadhyay AK, et al. Unique Clones of Vibrio cholerae $\mathrm{O} 1 \mathrm{El}$ Tor with Haitian Type ctxB Allele Implicated in the Recent Cholera Epidemics from Nigeria, Africa. PLoS One. 2016;11:e0159794.

58. Marin MA, Thompson CC, Freitas FS, Fonseca EL, Aboderin AO, Zailani SB, et al. Cholera Outbreaks in Nigeria Are Associated with Multidrug Resistan Atypical El Tor and Non-O1/Non-O139 Vibrio cholerae. PLoS Negl Trop Dis. 2013;7:e2049.

59. Hu D, Liu B, Feng L, Ding P, Guo X, Wang M, et al. Origins of the current seventh cholera pandemic. Proc Natl Acad Sci. 2016;113:E7730-9.

60. Mandal S, DebMandal M, Pal NK. Plasmid mediated antibiotic resistance of Vibrio cholerae $\mathrm{O} 1$ biotype El Tor serotype Ogawa associated with an outbreak in Kolkata, India. Asian Pac J Trop Med. 2010;3:637-41.

61. Dengo-Baloi LC, Semá-Baltazar CA, Manhique LV, Chitio JE, Inguane DL, Langa JP. Antibiotics resistance in El Tor Vibrio cholerae 01 isolated during cholera outbreaks in Mozambique from 2012 to 2015. PLoS One. 2017;12: e0181496.

62. Usman A, Sarkinfada F, Mufunda J, Nyarango P, Mansur K, Daiyabu TM Recurrent cholera epidemics in Kano-northern Nigeria. Cent Afr J Med. 2005;51:34-8.

63. Eisenberg MC, Kujbida G, Tuite AR, Fisman DN, Tien JH. Examining rainfall and cholera dynamics in Haiti using statistical and dynamic modeling approaches. Epidemics. 2013;5:197-207.

64. Camacho A, Bouhenia M, Alyusfi R, Alkohlani A, Naji MAM, de Radiguès X, et al. Cholera epidemic in Yemen, 2016-18: an analysis of surveillance data. Lancet Glob Health. 2018;6:e680-90.

65. de Magny G, Murtugudde R, Sapiano M, Nizam A, Brown C, Busalacchi A, et al. Environmental signatures associated with cholera epidemics. PNAS 2008;105:17676-81.

66. Baracchini T, King AA, Bouma MJ, Rodó X, Bertuzzo E, Pascual M. Seasonality in cholera dynamics: a rainfall-driven model explains the wide range of patterns in endemic areas. Adv Water Resour. 2017:108:357-66.

67. Lemaitre J, Pasetto D, Perez-Saez J, Sciarra C, Wamala JF, Rinaldo A. Rainfall as a driver of epidemic cholera: comparative model assessments of the effect of intra-seasonal precipitation events. Acta Trop. 2019;190:235-43.

68. Constantin de Magny G, Thiaw W, Kumar V, Manga NM, Diop BM, Gueye L, et al. Cholera Outbreak in Senegal in 2005: Was Climate a Factor? PLoS One. 2012;7:e44577.

69. Reyburn R, Kim DR, Emch M, Khatib A, von Seidlein L, Ali M. Climate variability and the outbreaks of cholera in Zanzibar, East Africa: a time series analysis. Am J Trop Med Hyg. 2011;84:862-9.

70. Fatiregun AA, Isere EE, Ayede Al, Olowookere SA. Epidemiology of an outbreak of cholera in a south-west state of Nigeria : brief report. South African J Epidemiol Infect. 2012;27:201-4.

71. Piarroux R, Barrais R, Faucher B, Haus R, Piarroux M, Gaudart J, et al. Understanding the cholera epidemic. Haiti Emerg Infect Dis. 2011;17:1161-8.

72. Kouadio IK, Aljunid S, Kamigaki T, Hammad K, Oshitani H. Infectious diseases following natural disasters: prevention and control measures. Expert Rev Anti-Infect Ther. 2012;10:95-104.

73. Sur D, Dutta P, Nair GB, Bhattacharya SK. Severe cholera outbreak following floods in a northern district of West Bengal. Indian J Med Res. 2000;112: 178-82.

74. Rieckmann A, Tamason CC, Gurley ES, Rod NH, PKM J. Exploring Droughts and Floods and Their Association with Cholera Outbreaks in Sub-Saharan Africa: A Register-Based Ecological Study from 1990 to 2010. Am J Trop Med Hyg. 2018;98:1269-74.

75. Wilson AM. The spread of cholera to and within Nigeria 1970-71. J Clin Pathol. 1971:24:768.

76. Yates T, Vujcic JA, Joseph ML, Gallandat K, Lantagne D. Efficacy and effectiveness of water, sanitation, and hygiene interventions in emergencies in low- and middle-income countries: a systematic review. Waterlines Practical Action Publishing. 2018:37:31-65.

\section{Publisher's Note}

Springer Nature remains neutral with regard to jurisdictional claims in published maps and institutional affiliations.
Ready to submit your research? Choose BMC and benefit from:

- fast, convenient online submission

- thorough peer review by experienced researchers in your field

- rapid publication on acceptance

- support for research data, including large and complex data types

- gold Open Access which fosters wider collaboration and increased citations

- maximum visibility for your research: over $100 \mathrm{M}$ website views per year

At BMC, research is always in progress.

Learn more biomedcentral.com/submissions 